\title{
Overview of nutritional strategies to lower enteric methane emissions in ruminants
}

\author{
Alireza Bayat and Kevin J. Shingfield \\ Animal Production Research, MTT, FI 31600, Jokioinen, Finland \\ email: firstname.lastname@mtt.fi
}

\begin{abstract}
Since ruminants are capable of utilizing fibrous feeds not digested by mono-gastrics, they represent a valuable natural resource for meeting future increases in global food supply. Ruminants have both local (nitrogen and phosphorus pollutions) and global (greenhouse gases, GHG) environmental footprints. It is estimated that the livestock sector is responsible for $18 \%$ of global anthropogenic GHG emissions. Losses of methane represent 30 to $50 \%$ of total GHG from livestock production, with the contribution from ruminants accounting for about $80 \%$. Due to the concerns of increases in GHG emissions into the environment and potential effects on global warming, there is a need to develop strategies to lower methane emissions from ruminants as part of an overall requirement to improve the sustainability of ruminant food production systems. Methane is produced as a by-product of anaerobic fermentation in the reticulo-rumen, largely due to the activity of methanogenic archaea. Recent research has focused on the potential of novel feed ingredients (probiotics, ionophores, acetogen-based inoculants, bacteriocins, organic acids and plant extracts) or vaccines to lower hydrogen production and/or increase the transfer and utilization of metabolic hydrogen in the production of end-products other than methane in the rumen. Research to date has provided evidence that dietary supplements of plant or marine oils, oilseeds, specific fatty acids and condensed tannins, as well as defaunation, increases in production level or decreases in the proportion of forage in the diet may lower enteric methane production. Even though dietary lipid supplements can be used to lower methane output, in high amounts a decrease in intake and milk production can be expected. While further investigations have demonstrated the efficacy of specific agents on methanogenesis in vitro, the effects have not been substantiated in vivo. Altering the ratio of $\mathrm{H}_{2} /$ non$\mathrm{H}_{2}$ producing fibrolytic bacteria to lower methanogenesis without altering fibre digestion has been demonstrated under experimental conditions. Furthermore, non- $\mathrm{H}_{2}$ producing communities have been characterized in the digesta of certain ruminant species. In contrast, stimulating acetogenesis by inoculation with rumen acetogens or non-rumen acetogens have met with limited success in vitro and in vivo. Research has also concentrated on stimulating the ultilisation of metabolic hydrogen by sulphate reducing bacteria, but there remains concern over the toxicity of $\mathrm{H}_{2} \mathrm{~S}$ in the host ruminant. Investigations of nitrate reducing bacteria which produce more $\mathrm{NH}_{3}$ and less toxic nitrite, have indicated promising results. Increasing the number of capnophilic bacteria which use $\mathrm{CO}_{2}$ and $\mathrm{H}_{2}$ to produce organic acids, succinic acid in particular, may decrease methane production. In isolation, several approaches have been shown to decrease enteric methane emissions, but often part of the changes observed are related to lowered organic matter digestion in the rumen. However, lowering methane production per unit product over the lifetime of an animal should be regarded as the central goal to decrease GHG from ruminant livestock systems. This highlights the need for integrated solutions to improve digestive efficiency, as well as fertility and health. In conclusion, any prospective solution to lower on-farm GHG emissions must be practical, cost effective and have no adverse effect on the profitability of ruminant meat and milk production. Recent research has indicated significant potential, but none of the strategies tested thus far satisfy all of the necessary criteria for immediate implementation.
\end{abstract}

Key words: Methane, Ruminants, Nutritional strategy 


\section{Introduction}

The demand for meat and milk is predicted to almost double by 2050 (Steinfeld et al., 2006) due to increases in the global population and increased consumption of these foods in developing countries. Ruminants that are capable of utilizing fibrous feeds, not digested by mono-gastrics, represent a valuable natural resource to meet global food requirements in the future. However, ruminants contribute to both local (nitrogen and phosphorus) and global (greenhouse gases (GHG; collectively $\mathrm{CH}_{4}, \mathrm{CO}_{2}$ and $\mathrm{N}_{2} \mathrm{O}$ ) emissions into the environment (Morgavi et al., 2010). Overall, the livestock sector is responsible for $18 \%$ of global anthropogenic GHG emissions (Steinfeld et al., 2006). Losses of methane $\left(\mathrm{CH}_{4}\right)$ represent 30 to $50 \%$ of total GHG from animal livestock production systems, with the contribution from ruminants accounting for about $80 \%$ (Gill et al., 2010). Due to the concerns of increases in GHG emissions into the environment and potential effects on global warming, there is a need to develop strategies to lower $\mathrm{CH}_{4}$ emissions from ruminants, as part of an overall requirement to secure and develop more sustainable ruminant food production systems in the future. Over a wide range of diets, enteric $\mathrm{CH}_{4}$ accounts for between 2 to $12 \%$ of dietary energy intake (Johnson and Johnson, 1995). In addition to concerns on GHG emissions, it is important to recognize that $\mathrm{CH}_{4}$ represents a significant loss of energy that could potentially be repartitioned towards tissues or the mammary gland. In attempting to mitigate both local and global emissions into the environment, research should arguably be directed towards lowering enteric $\mathrm{CH}_{4}$ and $\mathrm{CO}_{2}$ as well as $\mathrm{N}_{2} \mathrm{O}$ per unit product as well as increasing animal longevity This highlights the need for integrated solutions that do not simply focus on improved digestive efficiency in isolation, but also target improvements in fertility and animal health. In the following short review, both established and emerging nutritional strategies to lower ruminant enteric $\mathrm{CH}_{4}$ emissions are considered.

\section{Strategies to lower enteric methane emissions}

Methane is produced as a by-product of anaerobic fermentation in the reticulo-rumen of ruminants due, in a large part, to the activity of methanogenic archaea. Due to the complexity of the rumen microbial ecosystem, other microorganisms also regulate and alter $\mathrm{CH}_{4}$ production (Morgavi et al., 2010). Existing strategies to lower enteric $\mathrm{CH}_{4}$ emissions include increasing feed intake, proportion of concentrates in the diet, feeding high-quality forages or dietary supplements of plant and marine oils, oilseeds or specific fatty acids and ionophores. Recent research has focused on the potential of novel feed ingredients (probiotics, acetogens, bacteriocins, archaeal viruses, organic acids and plant extracts), vaccination of host animal against some methanogenic bacteria and the selection of cows with inherently lower losses of $\mathrm{CH}_{4}$ as a proportion of dietary energy intake (Boadi et al., 2004).

Losses of $\mathrm{CH}_{4}$ as a percentage of gross energy intake decreases $1.6 \%$ for each multiple of maintenance intake (Johnson and Johnson, 1995). The benefits of higher intakes are, at least in part, due to changes in rumen digestion kinetics. Mean retention time in the rumen is thought to explain about $28 \%$ of variation in $\mathrm{CH}_{4}$ production (Okine et al., 1989). Decreases in enteric $\mathrm{CH}_{4}$ emissions in response to increases in concentrate supplementation are thought to arise from several factors including a reduction in the molar acetate:propionate ratio of rumen volatile fatty acids, decreases in rumen $\mathrm{pH}$ and lowered protozoal numbers (Martin et al., 2010).

Supplementing diets with lipids is arguably one of the most practical and effective strategies to lower enteric $\mathrm{CH}_{4}$ emissions in ruminants. Based on an extensive evaluation of available data, it was reported that lipid supplements decrease enteric $\mathrm{CH}_{4}$ output on average by $3.8 \%$ per $1 \%$ dry matter (DM) increase in dietary fat content (Martin et al., 2010). While dietary lipid supplements have been shown to lower $\mathrm{CH}_{4}$, most studies have been relatively short in duration, and there are few data on the efficacy over an extended period (Martin et al., 2010). A summary of trials conducted in New Zealand reported that dietary supplements of a mixture of sunflower and fish oil $(500 \mathrm{~g} / \mathrm{d})$ over a $14 \mathrm{~d}$ period lowered $\mathrm{CH}_{4}$ by $27 \%$, while no change in $\mathrm{CH}_{4}$ was observed in cows fed $300 \mathrm{~g} / \mathrm{d}$ of linseed oil and fish oil for $77 \mathrm{~d}$ (Woodward $e t$ al., 2006). It remains unclear if the inhibitory effects of fatty acids on rumen methanogenesis persist for long periods, or whether microbial communities in the rumen adapt over time. While dietary lipid supplements decrease enteric $\mathrm{CH}_{4}$ production, feeding oils in high amounts $(\geq 50 \mathrm{~g} / \mathrm{kg}$ diet DM) often 
lower feed intake and milk production (Martin et al., 2008; Hristov et al., 2011). Overall, dietary fat addition results in the most consistent decrease in $\mathrm{CH}_{4}$ relative to changes in the forage:concentrate ratio of the diet or other feed additives, that when fed in moderate amounts can lower GHG without compromising the performance of growing or lactating cattle (Grainger and Beauchemin, 2011).

Ionophores such as monensin cause a moderate but transitory inhibition of rumen methanogenesis. Decreases in $\mathrm{CH}_{4}$ to ionophores are related to a reduction in rumen protozoal numbers (Guan et al., 2006), and alterations in ruminal bacterial populations, i.e. inhibition of the growth of Ruminococci without affecting F. Succinogenes (Chen and Wolin, 1979). Since January 2006 the use of ionophores in animal feeds has been banned in the European Union. It has been suggested that the relationship between the diversity of cellulolytic microorganisms in the rumen and $\mathrm{CH}_{4}$ production merits further investigation, based on evidence that metabolic hydrogen and $\mathrm{CH}_{4}$ production can be decreased in the absence of lowered fibre digestion (Morgavi et al., 2010).

Altering the ratio of $\mathrm{H}_{2}$ /non- $\mathrm{H}_{2}$ producing fibrolytic bacteria to lower methanogenesis without altering fibre digestion has been demonstrated under experimental conditions (Morgavi et al., 2010). This concept is supported based on evidence of the occurrence of dominant non- $\mathrm{H}_{2}$ producing microbial communities in the rumen of certain feral ruminants. Populations of non- $\mathrm{H}_{2}$ producing fibrolytic bacteria (Fibrobacter) were found to be higher and that of methanogens were lower than expected in rumen contents of buffaloes under natural conditions (Morgavi et al., 1994). Furthermore, non- $\mathrm{H}_{2}$ producing fibrolytic bacteria have been shown to produce less $\mathrm{CH}_{4}$ in vitro (Chaucheyras-Durand et al., 2010).

A meta-analysis concluded that probiotic live yeasts have no effect on $\mathrm{CH}_{4}$ production (Sauvant, 2005). However, the findings of other studies indicate that probiotic yeasts have variable effects on $\mathrm{CH}_{4}$ emissions (Doreau and Jouany, 1998; Chaucheyras-Durand et al., 2008), due to functional and metabolic diversity between specific strains (Newbold and Rode, 2006). In light of the significant genetic diversity between yeast strains, the potential of these feed additives to lower $\mathrm{CH}_{4}$ emissions merits further investigation (Martin et al., 2010).

Certain bacteriocins including nicin and bovicin have been tested in vitro or in vivo. Most evaluations are based on functional studies in vitro with few data in vivo, highlighting that much more information on the stability and efficacy of bacteriocins in ruminants is required before these can be used on-farm (Martin et al., 2010). Some time ago, it was suggested that archaeal viruses that act against rumen methaogenes could be used to decrease $\mathrm{CH}_{4}$ production (Klieve and Hegarty, 1999), but thus far, these have not yet been isolated and/or identified in the scientific literature (Martin et al., 2010).

Dietary supplementation of $100 \mathrm{~g}$ fumaric acid $/ \mathrm{kg}$ diet DM in free or encapsulated form was shown to decrease $\mathrm{CH}_{4}$ by $62 \%$ and $76 \%$, respectively in growing lambs (Wood et al., 2009). In contrast, other studies have reported that fumaric acid supplements had no effect on $\mathrm{CH}_{4}$ emissions when fed at $175 \mathrm{~g} / \mathrm{d}$ to growing beef cattle (Beauchemin and McGinn, 2006), at $80 \mathrm{~g} / \mathrm{d}$ to steers (McGinn et al., 2004) or between 4-10 g/100 g (diet DM) in lambs (Molano et al., 2008). Other investigations have examined the potential of organic acids to serve as alternative hydrogen sinks to $\mathrm{CH}_{4}$ in the rumen. Dietary supplements of DL-malic acid (from 0 to $75 \mathrm{~g} / \mathrm{kg}$ diet DM) were reported to decrease linearly $\mathrm{CH}_{4}$ production in beef cattle, changes that were also accompanied by lowered DM intake, total rumen VFA production and molar acetate to propionate ratios (Foley et al., 2009a). It has been speculated that the potential of organic acids to lower $\mathrm{CH}_{4}$ may depend on the forage to concentrate ratio of the diet (Foley et al., 2009b). Further experiments are required to define conditions that optimize the efficacy of organic acids in the rumen and the persistency of their effects on rumen methanogenesis (Hook et al., 2010).

Three main plant compounds, condensed tannins, saponins, and essential oils, have been identified as effective for lowering $\mathrm{CH}_{4}$ production in vitro (Martin et al., 2010). Tannins are classified into two groups; condensed tannins and hydrolysable tannins. The anti-methanogenic activity of tannins has been attributed mainly to condensed tannins, whereas hydrolysable tannins are considered toxic to the host ruminant (Martin et al., 2010). Two different mechanisms explaining the mode of action of condensed tannins on $\mathrm{CH}_{4}$ have been described; a direct effect on ruminal methanogens and an indirect effect on hydrogen production due to lower feed degradation in the rumen (Tavendale et al., 2005). Condensed tannins are 
found in tropical shrub legumes including Lotus spp. and Acacia spp. Dietary supplements of plants or extracts of condensed tannins have variable effects on $\mathrm{CH}_{4}$ production (0 to -30\%) in ruminants (Martin et al., 2010). Adding condensed tannins to the diet cannot be assumed to lower rumen methanogenesis, and their use requires further research.

Saponins, a group of secondary compounds, are found in many plants. These glycosides have a direct effect on rumen microbes and decrease protein degradation and increase microbial protein synthesis in the rumen (Makkar and Becker, 1996), changes that lower the availability of hydrogen for $\mathrm{CH}_{4}$ production. Furthermore, saponins have been shown to increase ruminal concentrations of propionate at the expense of acetate and butyrate (Abreu et al., 2004) that would be expected to decrease $\mathrm{CH}_{4}$ production.

In the recent years, several investigations have explored the potential of essential oils to lower $\mathrm{CH}_{4}$ in vitro. Essential oils are steam-volatile or organic-solvent extracts of plants (often herbs and spices) containing cyclic hydrocarbons and their alcohol, aldehyde or ester derivatives (Patra and Saxena, 2009).

Essential oils are lipophilic and interact with cell membranes which accounts for anti-bacterial and anti-fungal properties (Patra and Saxena, 2009). Components in essential oils are particularly toxic to gram positive bacteria (Jouany and Morgavi, 2007) and therefore, are capable of influencing rumen fermentation patterns. Garlic oil and some of its constituents have been shown to decrease $\mathrm{CH}_{4}$ production in vitro due to the toxicity of organosulphur compounds such as diallyl sulphide and allicin on methanogens (Busquet et al., 2005; Macheboeuf et al., 2006). Supplementing the diet with $1 \mathrm{~g} / \mathrm{d}$ of essential oils and spice extracts was demonstrated to have no on $\mathrm{CH}_{4}$ output or alter feed digestibility in heifers (Beauchemin and McGinn, 2006), while further investigations in vivo are required to assess the efficacy, persistency and toxicity of these compounds in ruminants (Calsamiglia et al., 2007).

A vaccine against three selected methanogens has been developed in Australia. Immunization in sheep lowered $\mathrm{CH}_{4}$ production by $8 \%$, while further testing failed to confirm efficacy in other geographical regions (Wright et al., 2004).

It is possible to suppress the activity of rumen methanogenes with chemical agents including halogenated $\mathrm{CH}_{4}$ analogues. Drenching cows with chloroform resulted in a dramatic initial decrease in $\mathrm{CH}_{4}$ production and methanogen populations, but rumen methanogenesis gradually recovered from 5 to 39 days of treatment, suggesting resistance or adaptation of affected microbes over time (Knight et al., 2011). However, use of this approach cannot be considered practicable, since chloroform is a known carcinogen and exhibits hepatotoxic properties (Knight et al., 2011).

\section{Repartitioning metabolic hydrogen in the rumen}

When methanogenesis is inhibited, $\mathrm{H}$ ions must be utilised in other metabolic pathways in the rumen to avoid negative effects on fermentation (Knight $e t$ al., 2011). Increasing acetogenesis by natural rumen acetogens or non-rumen acetogens have met with limited success in vitro and in vivo (Morgavi et al., 2010). The potential of increasing metabolic hydrogen use by sulphate reducing bacteria has been examined, but there is serious concern over the production of $\mathrm{H}_{2} \mathrm{~S}$ as an end-product due to toxic effects in the host ruminant (Gould et al., 1997). Nitrate is another possible sink for hydrogen produced during rumen carbohydrate fermentation, but the reduction of nitrate results in the production of nitrite, which is both toxic to ruminants and slowly converted to $\mathrm{NH}_{3}$ in the rumen. Investigations of nitrate reducing bacteria which produce more $\mathrm{NH}_{3}$ and less toxic nitrite, have indicated promising results (Iwamoto et al., 2002; Sar et al., 2005). Increasing the number of capnophilic bacteria which use $\mathrm{CO}_{2}$ and $\mathrm{H}_{2}$ to produce organic acids, succinic acid in particular, may decrease $\mathrm{CH}_{4}$ production. While further studies have demonstrated the efficacy of specific agents on methanogenesis in vitro, but there is insufficient data in vivo to confirm the potential of these agents to lower $\mathrm{CH}_{4}$ in practice.

\section{Conclusions}

Proposed strategies to lower on-farm $\mathrm{CH}_{4}$ emissions must be practical, cost effective, sustainable and have no substantial adverse effect on the profitability of ruminant livestock production in order to be considered viable. Manipulating diet composition to induce changes in rumen fermentation characteristics 
remains the most feasible approach to achieve immediate decreases in $\mathrm{CH}_{4}$ production. However, lowering $\mathrm{CH}_{4}$ production per unit product over the lifetime of productive ruminants should be seen as the central goal to decrease GHG emissions of ruminant livestock systems. This highlights the need for integrated solutions that not only result in improved digestive efficiency, but also target improvements in fertility and animal health as a means to extend ruminant productive lifetime. While recent research has indicated significant potential, none of the strategies tested satisfy all of the necessary criteria for immediate implementation.

\section{References}

Abreu, A., Carulla, J.E., Lascano, C.E., Diaz, T.E., Kreuzer, M. \& Hess, H.D. 2004. Effects of Sapindus saponaria fruits on ruminal fermentation and duodenal nitrogen flow of sheep fed a tropical grass diet with and without legume. J. Anim. Sci. 82: 1392-1400.

Beauchemin, K.A. \& McGinn, S.M. 2006. Methane emissions from beef cattle: Effects of fumaric acid, essential oil, and canola oil. J. Anim. Sci. 84: 1489-1496.

Boadi, D., Benchaar, C., Chiquette, J. \& Masse, D. 2004. Mitigation strategies to reduce enteric methane emissions from dairy cows: Update review. Can. J. Anim. Sci. 84: 319-335.

Busquet, M., Calsamiglia, S., Ferret, A. \& Kamel, C. 2005. Screening for the effects of natural plant extracts and secondary plant metabolites on rumen microbial fermentation in continuous culture. Anim. Feed Sci. Technol. 123: 597-613.

Calsamiglia, S., Busquet, M., Cardozo, P.W., Castillejos, L. \& Ferret, A. 2007. Invited review: essential oils as modifiers of rumen microbial fermentation. J. Dairy Sci. 90: 2580-2595.

Chaucheyras-Durand, F., Masseglia, S., Fonty, G. \& Forano, E. 2010. Influence of the composition of the cellulolytic flora on the development of hydrogenotrophic microorganisms, hydrogen utilization, and methane production in the rumens of gnotobiotically reared lambs. App. Environ. Microbiol. 76: 79317937.

Chaucheyras-Durand, F., Masseglia, S., Fonty, G. \& Forano, E. 2008. Development of hydrogenotrophic microorganisms and $\mathrm{H}_{2}$ utilisation in the rumen of gnotobiotically-reared lambs. Influence of the composition of the cellulolytic microbial community and effect of the feed additive Saccharomyces cerevisiae I-1077. In: Proceedings of the 6th INRA-RRI symposium. Gut microbiome: functionality, interaction with the host and impact on the environment, Clermont-Ferrand, France, pp. 48-49.

Chen, M. \& Wolin, M.J. 1979. Effect of monensin and lasalocid-sodium on the growth of methanogenic and rumen saccharolytic bacteria. Appl. Environ. Microbiol. 38: 72-77.

Doreau, M. \& Jouany, J.P. 1998. Effect of a Saccharomyces cerevisiae culture on nutrient digestion in lactating dairy cows. J. Dairy Sci. 81: 3214-3322.

Foley, P.A., Kenny, D.A., Callan, J.J., Boland, T.M. \& O'Mara F.P. 2009a. Effect of DL-malic acid supplementation on feed intake, methane emission, and rumen fermentation in beef cattle. J. Anim. Sci. 87: 1048-1057.

Foley, P.A., Kenny, D.A., Lovett, D.K., Callan, J.J., Boland, T.M. \& O'Mara F.P. 2009b. Effect of DLmalic acid supplementation on feed intake, methane emissions, and performance of lactating dairy cows at pasture. J. Dairy Sci. 92: 3258-3264.

Gill, M., Smith, P. \& Wilkinson, J.M. 2010. Mitigating climate change: the role of domestic livestock. Animal 4: 323-333.

Gould, D.H., Cummings, B.A. \& Hamar, D.W. 1997 In vivo indicators of pathologic ruminal sulphide production in steers with diet-induced polioencephalomalacia. J. Vet. Diag. Invest. 9: 72-76.

Grainger, C. \& Beauchemin, K.A. 2011. Can enteric methane emissions from ruminants be lowered without lowering their production? Anim. Feed Sci. Technol. 166: 308-320.

Guan, H., Wittenberg, K.M., Ominski, K.H., \& Krause, D.O. 2006. "Efficacy of ionophores in cattle diets for mitigation of enteric methane," J Anim. Sci. 84: 1896-1906.

Hook, S.E., Wright, A.D.G. \& McBride, B.W. 2010. Methanogens: methane producers of the rumen and mitigation strategies. Archaea doi: 10.1155/2010/945785. 
Hristov, A.N., Domitrovich, C., Wachter, A., Cassidy, T., Lee, C., Shingfield, K.J., Kairenius, P., Davis, J. \& Brown, J. 2011. Effect of replacing solvent-extracted canola meal with high-oil traditional canola, high-oleic acid canola, or high-erucic acid rapeseed meals on rumen fermentation, digestibility, milk production, and milk fatty acid composition in lactating dairy cows. J. Dairy Sci. 94: 4057-4074.

Iwamoto, M., Asanuma, N. \& Hino, T. 2002. Ability of Selenomonas ruminantium, Veillonella parvula, and Wolinella succinogenes to reduce nitrate and nitrite with special reference to the suppression of ruminal methanogenesis. Anaerobe 8: 209-215.

Johnson, K.A. \& Johnson, D.E. 1995. Methane emissions from cattle. J. Anim. Sci. 73, 2483-2492.

Jouany, J.P. \& Morgavi, D.P. 2007. Use of 'natural' products as alternatives to antibiotic feed additives in ruminant production. Animal 1: 1443-1466.

Klieve, A. \& Hegarty, R.S. 1999. Opportunities for biological control of methanogenesis. In: P.J. Reyenga and S.M. Howden (edit.) Meeting the Kyoto Target. Implications for the Australian Livestock Industries. Bureau of Rural Sciences, pp 63-69.

Knight, T., Ronimus, R.S., Dey, D., Tootill, C., Naylor, G., Evans, P., Molano, G., Smith, A., Tavendale, M., Pinares-Patino, C.S. \& Clark, H. 2011. Chloroform decreases rumen methanogenesis and methanogen populations without altering rumen function in cattle. Anim. Feed Sci. Technol. 166: 101112.

Macheboeuf, D., Lassalas, B., Ranilla, M.J., Carro, M.D. \& Morgavi, D. 2006. Dose-response effect of diallyl disulfide on ruminal fermentation and methane production in vitro. Reprod. Nut. Develop. 46 (Suppl. 1): S103.

Makkar, H.P.S. \& Becker, K. 1996. Effect of pH, temperature, and time on inactivation of tannins and possible implications in detannification studies. J. Agric. Food Chem. 44: 1291-1295.

Martin, C., Morgavi, D.P. \& Doreau, M. 2010. Methane mitigation in ruminants: from microbe to the farm scale. Animal 4, 351-365.

Martin, C., Rouel, J., Jouany, J.P., Doreau, M., \& Chilliard, Y. 2008. Methane output and diet digestibility in response to feeding dairy cows crude linseed, extruded linseed, or linseed oil. J. Anim. Sci. 86: 2642-2650.

McGinn, S.M., Beauchemin, K.A., Coates, T. \& Colombatto, D. 2004. Methane emissions from beef: effects of monensin, sunflower oil, enzymes, yeast and fumaric acid. J. Anim. Sci. 82: 3346-3356.

Molano, G., Knight, T.W. \& Clark, H. 2008. Fumaric acid supplements have no effect on methane emissions per unit of feed intake in wether lambs. Aust. J. Exp. Agric. Sci. 48: 165-168.

Morgavi, D.P., Forano, E., Martin, C. \& Newbold, C.J. 2010. Microbial ecosystem and methanogenesis in ruminants. Animal 4: 1024-1036.

Morgavi, D.P., Sakurada, M., Tomita,Y. \& Onodera, R. 1994. Presence in rumen bacterial and protozoal populations of enzymes capable of degrading fungal cell walls. Microbiol. (UK) 140: 631-636.

Newbold, C.J. \& Rode, L.M. 2006. Dietary additives to control methanogenesis in the rumen. In: Soliva, C.R., Takahashi, J., Kreuzer, M. (edit.), Greenhouse Gases and Animal Agriculture: An Update. Elsevier International Conference Series 1293. Elsevier, Amsterdam, The Netherlands, pp. 138-147.

Okine, E.K., Mathison, G.W. \& Hardin, R.T. 1989. Effects of changes in frequency of reticular contractions on fluid and particulate passage rates in cattle. J. Anim. Sci. 67: 3388-3396.

Patra, A.K. \& Saxena, J. 2009. Dietary phytochemicals as rumen modifiers: a review of the effects on microbial populations. Anton. Van Leeuw. 96: 363-375.

Sar, C., Mwenya, B., Santoso, B., Takaura, K., Morikawa, R., Isogai, N., Asakura, Y., Toride, Y. \& Takahashi, J. 2005. Effect of Escherichia coli W3110 on ruminal methanogenesis and nitrate/nitrite reduction in vitro. Anim. Feed Sci. Technol. 118: 295-306.

Sauvant, D. 2005. Rumen acidosis: modeling ruminant response to yeast culture. In: T.P. Lyons and K.A. Jacques (edit.) Nutritional biotechnology in the feed and food industries, pp. 221-228. Nottingham University Press, Nottingham, UK. 
Steinfeld, H., Gerber, P., Wassenaar, T., Castel, V., Rosales, M. \& de Haan, C. 2006. Livestock's Long Shadow: Environmental Issues and Options. Food and Agriculture Organization of the United Nations (FAO), Rome, Italy.

Tavendale, M.H., Meagher, L.P., Pacheco, D., Walker, N., Attwood, G.T. \& Sivakumaran, S. 2005. Methane production from in vitro rumen incubations with Lotus pedunculatus and Meticago sativa, and effects of extractable condensed tannin fractions on methanogenesis. Anim. Feed Sci. Technol. 123: 403-419.

Wood, T.A., Wallace, R.J., Rowe, A., Price, J., Yanez-Ruiz, D.R., Murray, P. \& Newbold, C.J. 2009. Encapsulated fumaric acid as a feed ingredient to decrease ruminal methane emissions. Anim. Feed Sci. Technol. 152: 62-71.

Woodward, S.L., Waghorn, G.C. \&Thomson, N.A. 2006. Supplementing dairy cows with oils to improve performance and reduce methane-does it work? Proc. N. Z. Soc. Anim. Prod. 66: 176-181.

Wright, A.D.G., Kennedy, P., O’Neill, C.J., Toovey, A.F., Popovski, S., Rea, S.M., Pimm, C.L. \& Klein, L. 2004. Reducing methane emissions in sheep by immunization against rumen methanogens. Vaccine, 22: 3976-3985. 